\title{
Idebenone as a Novel Therapeutic Approach for Duchenne Muscular Dystrophy
}

\author{
Gunnar M Buyse, ${ }^{1}$ Nuri Gueven² and Craig M McDonald³ \\ 1. University Hospitals Leuven, Leuven, Belgium; 2. Pharmacy, School of Medicine, University of Tasmania, Hobart, Australia; \\ 3. University of California Davis Medical Center, Sacramento, US
}

\begin{abstract}
Progressive loss of pulmonary function leads to early morbidity and mortality in Duchenne muscular dystrophy (DMD) due to both expiratory impairment with ineffective airway clearance, and inspiratory impairment leading to nocturnal and daytime hypoventilation and respiratory failure. Glucocorticoid steroids have become a mainstay of DMD therapy with well-documented efficacy on muscle strength and respiratory function. However, the side-effect profile restricts their long-term use, particularly in non-ambulant patients. Idebenone improves secondary mitochondrial dysfunction caused by dystrophin deficiency, intracellular calcium accumulation and increased reactive oxygen species (ROS). Idebenone-mediated improved bioenergetics leads to enhanced adenosine triphosphate (ATP) production and reduced ROS. Based on this rationale, idebenone has been investigated clinically for efficacy on reducing respiratory function decline in exploratory phase II (DELPHI) and confirmatory phase III (DELOS) trials. Idebenone significantly reduced the loss of respiratory function in 8-18-year-old DMD patients who were not using concomitant glucocorticoids. These results indicate that idebenone can modify the natural course of respiratory disease progression in $\mathrm{DMD}$, which is relevant in clinical practice where loss of respiratory function continues to be a predominant cause of early morbidity and mortality in DMD.
\end{abstract}

\section{Keywords}

Duchenne muscular dystrophy, idebenone, respiratory function, peak expiratory flow, glucocorticoid steroid

\begin{abstract}
Disclosure: Gunnar M Buyse, Nuri Gueven and Craig M McDonald act as scientific consultants to Santhera Pharmaceuticals (Switzerland). Gunnar M Buyse was an investigator for clinical trials in Duchenne muscular dystrophy sponsored by GlaxoSmithKline, Prosensa and Santhera Pharmaceuticals and is Senior Clinical Investigator of the Research Foundation Flanders (FWO Vlaanderen, Belgium). He also is inventor of relevant patent applications. Craig M McDonald consulted on Duchenne muscular dystrophy clinical trials for Akashi Therapeutics, Biomarin, Bristol Myers Squibb, Cardero Therapeutics, Eli Lilly, Gilead, Italfarmaco, Mitobridge, Novartis, Pfizer, Prosensa, PTC Therapeutics, Santhera Pharmaceuticals and Sarepta Therapeutics.

Compliance with Ethics: The analysis in this article is based on previously conducted studies, and does not involve any new studies of human or animal subjects performed by any of the authors.

Acknowledgements: The authors thank the DELOS Study Group and all Duchenne muscular dystrophy patients and families who participated in the DELPHI and DELOS trials, Christian Rummey and Mika Leinonen (4Pharma, Switzerland and Sweden) for statistical analyses, Thomas Meier (Santhera Pharmaceuticals, Switzerland) for contributing to the manuscript and support in the preparation of figures and tables and Anna Carratu for editorial support.

open Access: This article is published under the Creative Commons Attribution Noncommercial License, which permits any non-commercial use, distribution, adaptation and reproduction provided the original author(s) and source are given appropriate credit.

Received: 23 May 2015 Accepted: 29 June 2015 Citation: European Neurological Review, 2015;10(2):189-94 http://doi.org/10.17925/ENR.2015.10.02.189

Correspondence: Gunnar M Buyse, Child Neurology, University Hospitals Leuven, Herestraat 49, B - 3000 Leuven, Belgium. E: gunnar.buyse@uzleuven.be
\end{abstract}

Support: Santhera Pharmaceuticals was the sponsor of the DELPHI and DELOS trials and supported this publication.

\section{Respiratory Function Loss and Respiratory Endpoints in DMD}

Duchenne muscular dystrophy (DMD) is the most common and devastating type of muscular dystrophy. Lack of the protein dystrophin causes severe and progressive myofibre degeneration, general muscle weakness and wasting. With increasing age, DMD patients are confronted with loss of ambulation, loss of upper limb function, cardiac dysfunction and dependence on mechanical airway clearance and mechanical assisted ventilation representing irreversible and lifechanging events of disease progression. Although early diagnosis and multi-stage disease management regimes (e.g. Bushby et al. . ${ }^{1,2}$ increase quality of life and life expectancy, the disease is still associated with early morbidity and mortality. In DMD, progressive weakness of the chest wall muscles precedes weakness of the diaphragm (used predominantly for inspiratory function) and leads to restrictive lung volume changes measured as reduced total lung capacity and forced vital capacity $(\mathrm{FVC}){ }^{3-7}$ Initially, this loss of lung volume results from the inability to pull up the respiratory system to total lung capacity and to push it down to residual volume. In later disease stages, additional restrictions occur as a result of progressing muscle fibrosis and changes in lung and chest wall recoil, thoracic wall compliance and spinal deformities (i.e. scoliosis).

In the late first decade the earliest signs of respiratory impairment manifest by reduced static airway pressures (maximal expiratory and inspiratory pressures). The gradual loss of respiratory function in DMD measured by spirometry usually begins early in the second decade and progresses to restrictive pulmonary syndrome, impaired respiratory secretion clearance, life-threatening pulmonary infections due to ineffective cough, nocturnal and daytime hypoventilation, obstructive apnoeas and eventually respiratory failure during the late second or third decade of life. .,8-10 $^{-10}$ 
Figure 1: Respiratory Function Decline in DMD
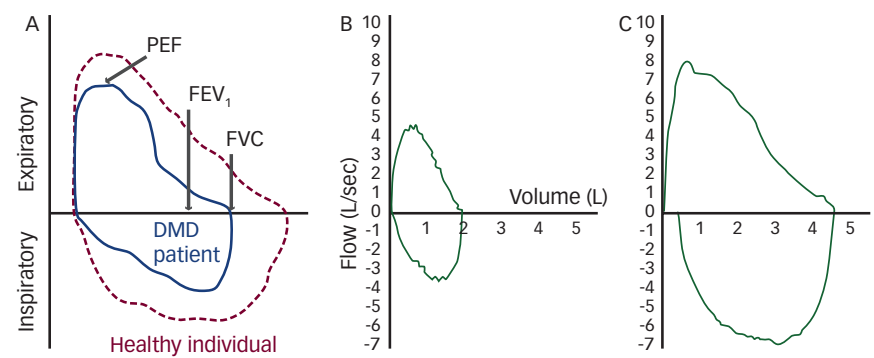

Schematic flow-volume curve of healthy individual (red) and Duchenne muscular dystrophy (DMD) patient (blue) measuring reduced peak expiratory flow (PEF) forced vital capacity (FVC) and forced expiratory volume in 1 second $\left(F E V_{1}\right)$. A. Flow-volume curve of an 18-year-old DMD patient (B) and age-matched subject with normal lung function (C). Figures (B) and (C) courtesy of Dr Oscar H Mayer, Division of Pulmonology, Children's Hospital of Philadelphia (US).

In the absence of obstructive pulmonary disease, FVC (measured in litres), peak expiratory flow (PEF, measured in $1 /$ minute), and forced expiratory volume in 1 second ( $F E V_{1}$, measured in litres) are major interrelated spirometry measures reflecting both inspiratory and expiratory muscle force impairment and restrictive lung volume changes due to neuromuscular weakness. In DMD both inspiratory and expiratory respiratory weakness is indicated by abnormal flow-volume curves (see Figure 1).

FVC is used to assess respiratory muscle involvement in many neuromuscular diseases, such as DMD. One may infer the presence of a restrictive ventilatory defect due to neuromuscular weakness when the $\mathrm{FVC}$ is reduced and the FEV, $/ F V C$ ratio is normal or increased. Previous studies have shown excellent test-retest reliability of FVC among DMD subjects. However, a limitation of FVC as a respiratory endpoint in DMD is that it is potentially affected by thoracic wall compliance/ fibrosis and thoracic deformities resulting from progressive scoliosis. FEV typically follows the decline measured in FVC. In the absence of obstructive pulmonary disease such as asthma, FEV 1 is also an indicator of respiratory impairment due to neuromuscular weakness of combined inspiratory and expiratory weakness.

In DMD patients who do not exhibit bronchial obstruction, PEF reflects expiratory muscle force. ${ }^{5}$ Abnormal respiratory mechanics in DMD are not limited to the lung and chest wall and may also involve the upper airways. ${ }^{6}$ Therefore, respiratory strength in DMD (assessed by PEF) is a measure not only of expiratory strength but also inspiratory effort and upper airway resistance, which are both abnormal in DMD..$^{11,12}$ There is a theoretical possibility that PEF may be more sensitive to a treatment intervention than FVC due to the impact of fibrosis and chest wall deformities on FVC. All three of these measures - PEF, FVC and FEV can be obtained with high reliability in DMD patients older than $\sim 8$ years.

As respiratory function tests are influenced by body growth and age, these measures are typically normalised to height-matched (PEF) ${ }^{13}$ or height- and age-matched ( $F V C$ and $\left.\mathrm{FEV}_{1}\right)^{14}$ normative populations and expressed as 'per cent predicted' values (PEF\%p, FVC\%p, FEV $\%$ p).

Recent care guidelines recommend changes in DMD disease management as soon as patients fall below certain thresholds in FVC. ${ }^{2,15-17}$ For example, preoperative training prior to surgical procedures and post-operative use of non-invasive ventilation should be strongly considered for patients with FVC $<50 \% p$, and is necessary for patients with FVC $<30 \% p$. Various levels of impairment of FVC have been reported to be prognostically associated with an increased risk of respiratory complications and death in DMD..$^{15,18}$

A similar method of categorising the severity of lung function impairment based on the FEV \%p values has been described..$^{19}$ These severity scores can be associated with performance, such as ability to work and function in daily life, morbidity and prognosis. ${ }^{20-23} \mathrm{~A}$ drop of $\mathrm{FEV}_{1} \% \mathrm{p}$ to below $40 \%$ was found to be a sensitive indicator of sleep hypoventilation in DMD. ${ }^{24}$ Thus, reduction in the rate of progression of $\mathrm{FEV}_{1} \% \mathrm{p}$ would be of direct clinical value to a patient with DMD in terms of slowing pulmonary disease progression and decreasing the likelihood of developing carbon dioxide retention.

More recently, peak cough flow (PCF) measures are obtained as part of standard of care. When PCF falls below $160 \mathrm{l} /$ minute, cough is no longer effective enough to provide adequate mucociliary clearance. ${ }^{25-27}$ According to published standard of care considerations, manual and mechanically assisted cough techniques are necessary when either respiratory infection is present and PCF is $<270 \mathrm{l} /$ minute, or in the absence of a respiratory infection when PCF is $<160 \mathrm{l} /$ minute. One of the challenges in PCF measures tends to be reduced reliability of testing in children and the difficulty of performing the test. ${ }^{25}$

In summary, PEF, FVC and $\mathrm{FEV}_{1}$ are three inter-related pulmonary parameters and reflect both inspiratory and expiratory muscle force impairment, and restrictive lung volume changes indicated by abnormal flow-volume curves in DMD. The \%-predicted values control for maturational changes longitudinally. PEF\%p, FVC\%p and FEV $\% p$ are also highly correlated in DMD and are all indicators of restrictive pulmonary disease due to neuromuscular weakness and are the most reliably assessed respiratory measures in this disease. Finally, natural history studies show that these are the only three respiratory function endpoints with consistent declines across the second decade in DMD from age $10-18$ years. $^{28,29}$

\section{Glucocorticoid Steroids - \\ A Delicate Benefit-Risk Balance}

There is agreement that patients with DMD generally benefit from glucocorticoid treatment, ${ }^{30}$ the therapeutic objective of which is to slow the decline in muscle strength and stabilise respiratory function. The effect of glucocorticoids on muscle strength has been shown to prolong ambulation $^{31,32}$ and continued treatment after the patient becomes nonambulatory has shown reduction in the risk of progressive scoliosis and stabilisation of respiratory test variables. ${ }^{33,34}$ These and the results of other clinical trials support the use of glucocorticoids, ${ }^{35}$ which have become the mainstay of disease management in $\mathrm{DMD} .^{1,2}$

However, the mode of action of steroids in DMD still is not entirely resolved and their chronic administration is associated with well-described significant risks, such as growth retardation, bone demineralisation and increased fracture risk, obesity, insulin resistance and hyperglycaemia, cutaneaous complications (acne, striae), arterial hypertension, cardiomyopathy, cataracts and important behavioral changes, such as increased anxiety and anger, ${ }^{1,36}$ which especially after the loss of ambulation, can negatively affect the benefit-risk balance of glucocorticoid use. Furthermore, while there are emerging data concerning benefits of long-term administration of steroids for preservation of upper limb and respiratory function, ${ }^{32,37}$ the effectiveness and risks of specific glucocorticoid treatment regiments in preventing scoliosis, maintaining upper limb function and stabilising respiratory function in the older non-ambulant patients with DMD has not been studied in 
Table 1: Mitochondrial Pathology in Dystrophin Deficient Muscle

- Increased intracellular $\mathrm{Ca}^{2+}$

- Functional aberration in key intracellular energy systems

- Depressed oxygen consumption rate

- Reduced OXPHOS capacity

- Decreased mitochondrial respiration rate

\begin{tabular}{|c|c|}
\hline & $\begin{array}{l}\text { Godin et al. }{ }^{50} \\
\text { Schuh et al. }{ }^{51} \\
\text { Percival et al. } .^{52}\end{array}$ \\
\hline - Reduction in resting ATP levels & $\begin{array}{l}\text { Cole et al. }{ }^{53} \\
\text { Rybalka et al. }{ }^{54}\end{array}$ \\
\hline $\begin{array}{l}\text { - } \text { Reduced mitochondrial Complex I function } \\
\text { - Decreased Complex I subunit content }\end{array}$ & $\begin{array}{l}\text { Godin et al. }{ }^{50} \\
\text { Percival et al. }{ }^{52} \\
\text { Rybalka et al. }{ }^{54}\end{array}$ \\
\hline $\begin{array}{l}\text { - Mitochondria from dystrophic muscle are } \\
\text { swollen and more susceptible to damage } \\
\text { - Increased fragility of inner and outer } \\
\text { mitochondrial membrane }\end{array}$ & $\begin{array}{l}\text { Millay et al. }{ }^{55} \\
\text { Rybalka et al. }{ }^{54}\end{array}$ \\
\hline
\end{tabular}

ATP = adenosine triphosphate; OXPHOS = oxidative phosphorylation.

controlled trials. At any time, approximately $40 \%$ of DMD patients are either glucocorticoid-naïve or have discontinued treatment, ${ }^{32}$ due to glucocorticoid side effects and partial treatment effect, and this proportion even increases in the later post-ambulatory phase. Therefore, many patients are left without pharmacological treatment options at around the age when patients become non-ambulatory and the decline in respiratory function becomes clinically relevant. In summary, there is an unmet medical need for the management of respiratory function deterioration in DMD patients not taking glucocorticoids or in patients who do not respond to glucocorticoid treatment.

\section{Rationale for Idebenone as Treatment Approach for DMD}

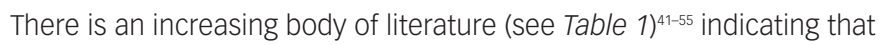
dystrophin deficiency causes sarcolemmal fragility and intracellular $\mathrm{Ca}^{2+}$ dysregulation, which generally leads to mitochondrial dysfunction, a reduction in resting adenosine triphosphate (ATP) levels, an increased production of cell-damaging reactive oxygen species (ROS) and ultimately mitochondrial damage. ${ }^{38-40}$

The combination of primary dystrophin deficiency and secondary mitochondrial dysfunction and impaired muscle cell regeneration, degeneration and cell death is shown in Figure 2A. Muscle membrane injury caused by dystrophin deficiency leads to increased calcium influx and intracellular calcium accumulation. Thus, the primary pathogenesis results in increased ROS and damage to and dysfunction of mitochondria with subsequent depletion of mitochondria over time.

Recently, Complex I function was shown to be deficient in mitochondria from the $m d x$ mouse and ATP production was ameliorated by stimulating complex $11 .{ }^{54}$ As direct evidence of a mitochondrial role in the pathogenesis of muscular dystrophy, mitochondrial biogenesis has been demonstrated to ameliorate the pathology and improve function in the dystrophin deficient $m d x$ mouse model. Specifically, Selsby and colleagues $^{56}$ showed that over-expression of peroxisome-proliferator receptor $\gamma$ coactivator $1 \alpha$ (PGC-1 $\alpha$ ), resulted in increased utrophin and

\section{Figure 2: Mitochondrial Dysfunction Resulting from Dystrophin Deficiency and Mode of Action of Idebenone}

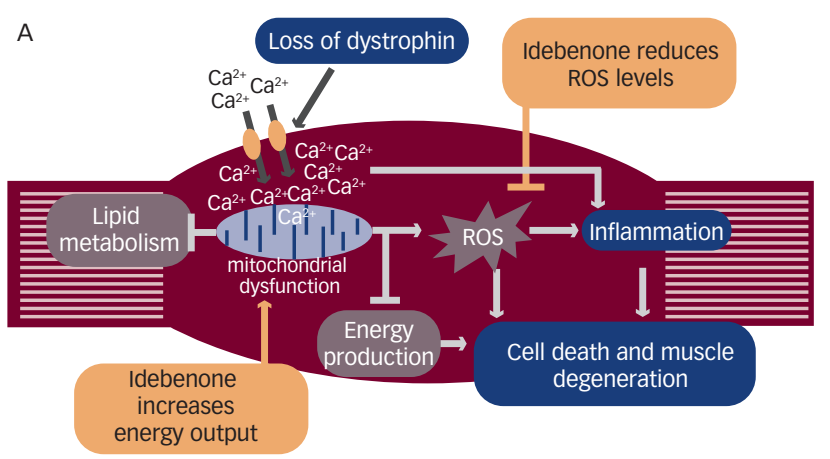

B

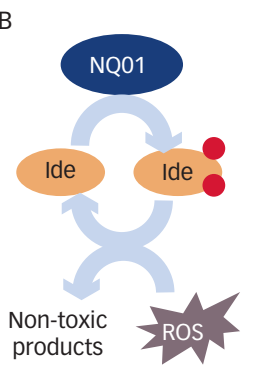

C

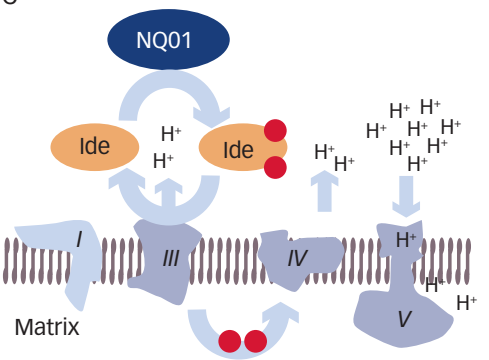

ATP

A. Schematic diagram of the mitochondrial dysfunction caused by dystrophin deficiency. Cytoplasmic calcium overload causes mitochondrial dysfunction, reduces cellular energy production and increases the production of reactive oxygen species (ROS) both of which are counteracted by idebenone. B, C. Dual mode of action of idebenone: Idebenone (Ide) is reduced by the cytoplasmic enzyme NQO1 (NAD(P) $H$ :quinone oxidoreductase or $N A D(P) H$ dehydrogenase, quinone 1; UniProt P15559) and can cross the mitochondrial membrane. B. Reduced idebenone can detoxify (ROS) by donating electrons (red spheres) to produce non-toxic reaction products. C. Idebenone can also donate electrons directly to complex III of the mitochondrial electron transport chain, which restores electron flow, proton pumping activity of complexes III and IV and adenosine triphosphate (ATP) production by complex V (the ATP synthase). Both processes are dependent on a continuous reduction by NQO1 and repeated shuttling of idebenone between the cytosol and mitochondria.

slow type I myosin heavy chain fibre expression, as well as elevated mitochondrial protein expression and increased expression of oxidative genes. These PGC-1 $\alpha$ over-expressing $m d x$ limb muscles were better able to maintain force during eccentric lengthening contractions compared with control limbs and demonstrated reduced disease-related muscle injury as measured by decreased areas of necrotic fibres and centrally nucleated fibres. In addition, it has long been known that mitochondrial depletion is associated with greater disease progression in DMD. ${ }^{57,58}$

Based on these findings, mitochondrial activation via stimulation of Complex II- or Complex III-mediated electron flux might be a therapeutic approach to overcome mitochondrial dysfunction in dystrophindeficient muscle.

Idebenone is a synthetic short-chain benzoquinone, chemically derived but clearly distinct from CoQ10 in its subcellular distribution and pharmacological action due to its shorter carbon-tail and terminal hydroxyl group resulting in higher hydrophilicity and the potential to cross membranes.59,60 Idebenone has been reported to utilise and activate complex I-independent metabolic pathways ${ }^{61-64}$ by the transfer of energy equivalents from the cytosol directly into the mitochondrial electron transport chain (ETC). Upon entering the cell, idebenone is efficiently reduced by the cytoplasmic enzyme NADH-quinone oxidoreductase 1 (NQO1) and the resulting reduced form of idebenone 


\section{Table 2: Overview of the DELPHI and DELOS Trials and Baseline Characteristics of Enrolled Patients}

\begin{tabular}{|c|c|c|c|c|}
\hline Study & \multicolumn{2}{|c|}{ Phase II - DELPHI ${ }^{1}$} & \multicolumn{2}{|c|}{ Phase III - DELOS² } \\
\hline First patient in & \multicolumn{2}{|c|}{ October 2005} & \multicolumn{2}{|l|}{ July 2009} \\
\hline Last patient out & \multicolumn{2}{|l|}{ August 2007} & \multicolumn{2}{|l|}{ January 2014} \\
\hline Treatment group & Idebenone & Placebo & Idebenone & Placebo \\
\hline $\begin{array}{l}\text { Patients }(\mathrm{n}) \text { randomised } \\
\text { and treated (ITT population) }\end{array}$ & 13 & 8 & 31 & 33 \\
\hline $\begin{array}{l}\text { Patients (n) without } \\
\text { concomitant } \\
\text { glucocorticoid use }\end{array}$ & 5 & 3 & 31 & 33 \\
\hline Age (years) & $13.4 \pm 2.1$ & $10.8 \pm 1.9$ & $13.5 \pm 2.7$ & $15.0 \pm 2.5$ \\
\hline Non-ambulatory patients & $6(46 \%)$ & $6(75 \%)$ & $28(90.3 \%)$ & $31(93.9 \%)$ \\
\hline
\end{tabular}

Baseline characteristics for patients not using concomitant glucocorticoids*

\begin{tabular}{lllll} 
PEF\%p & $55.0 \pm 24.6$ & $52.0 \pm 27.1$ & $53.5 \pm 10.3$ & $54.2 \pm 13.2$ \\
\hline FVC\%p & $61.8 \pm 24.8$ & $51.7 \pm 15.5$ & $55.3 \pm 15.8$ & $50.4 \pm 20.0$ \\
\hline FEV $\% p$ & $66.8 \pm 26.1$ & $57.0 \pm 16.5$ & $53.6 \pm 16.1$ & $49.5 \pm 20.6$
\end{tabular}

Data are mean $\pm S D$; ${ }^{1}$ Buyse et al., 2011; Buyse et al., 2013; ${ }^{2}$ Buyse et al., 2015. *Data are from hospital-based spirometry. FEV $1 \% p=$ forced expiratory volume in 1 second per cent predicted; FVC\% $=$ forced vital capacity; ITT = intent to treat; PEF\%p = peak expiratory flow per cent predicted.

enters the mitochondria where it transfers its electrons to complex III. This mechanism thereby bypasses complex I-dependent electron flow and as a result is able to produce ATP even in situations where Complex I is dysfunctional. ${ }^{60,62,63}$ Separately, idebenone has been reported

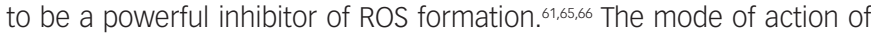
idebenone is illustrated in Figure $2 B, C$.

Idebenone significantly increased the daily running distance of $m d x$ mice and reduced cardiac inflammation and fibrosis in a long-term blinded placebo-controlled study. ${ }^{67}$ Idebenone also ameliorated cardiac diastolic dysfunction and reduced mortality from systolic cardiac pump failure in this model. Considering the generally accepted limitation of the $m d x$ mouse as an animal model for DMD, these potential benefits on skeletal muscle degeneration, endurance, and cardiac function would need to be confirmed in patients with DMD.

\section{Clinical Development of Idebenone as a Treatment Option for DMD}

Two randomised, placebo-controlled clinical trials were conducted to assess the efficacy and safety of idebenone on respiratory function outcomes in DMD (see Table 2). DELPHI was a phase II, single-centre study, ${ }^{68}$ while DELOS was an international, multicentre phase III study. ${ }^{69}$

The exploratory phase II DELPHI study reported a better outcome on $\mathrm{PEF} \% \mathrm{p}$ in the idebenone-treated group compared with the placebo group when all patients (irrespective of their concomitant glucocorticoid use) were analysed. ${ }^{68}$ However, in a post-hoc analysis is was found that the treatment effect of idebenone on respiratory function outcomes was considerably larger in patients not using concomitant glucocorticoids. ${ }^{70}$ This could be explained by the protective effect of glucocorticoids, challenging a formal demonstration of an additive effect on top of steroids within the limitations of a human clinical trial. Although the number of patients in the subgroup of patients not using glucocorticoids was too small to allow a firm conclusion, the expected influence of

\section{Figure 3: Outcomes on Respiratory Function from the DELOS Trial}

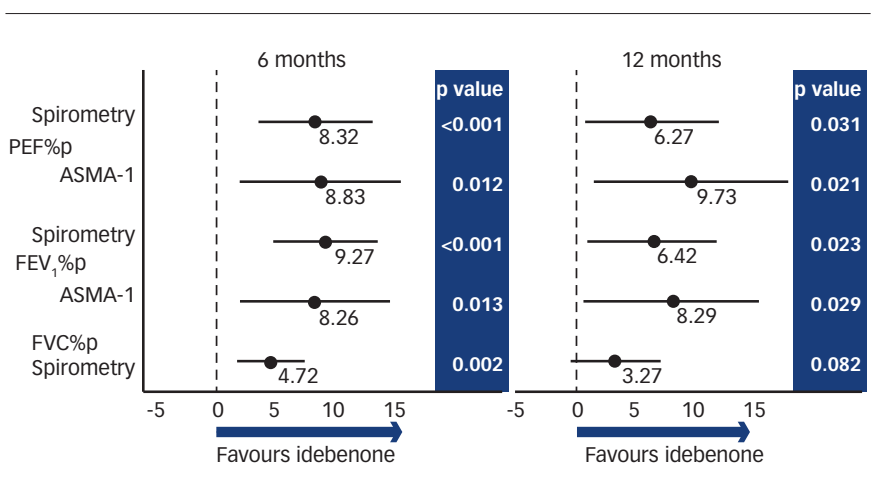

Treatment effect (estimated means from Mixed Model for Repeated Measures [MMRM] $95 \%$ confidence intervals, $p$ values) for respiratory function outcomes at the 6 - and 12-month time-points. Tests were performed by spirometry during hospital visits or weekly using a hand-held device (ASMA-1). FEV1\%p = forced expiratory volume in 1 second per cent predicted; FVC\%p = forced vital capacity; PEF\%p = peak expiratory flow per cent predicted.

\section{Table 3: Treatment Effect on Respiratory Function Parameters for Patients not using Concomitant Glucocorticoids Enrolled in DELPHI or DELOS (Combined Analysis; 12 months follow-up time)}

\begin{tabular}{|c|c|c|c|}
\hline Paramet & $\begin{array}{l}{ }^{1} \text { Idebenone, } \mathrm{n}=36 \\
\text { Age }^{2}: 13.5 \pm 2.6 \mathrm{Y}\end{array}$ & $\begin{array}{l}\text { Placebo, } n=36 \\
\text { Age }^{2:} 14.7 \pm 2.7 Y\end{array}$ & $\begin{array}{l}\text { Treatment Effect } \\
\text { (Estimated Mean, } \\
95 \% \text { Confidence } \\
\text { Interval) }{ }^{3}\end{array}$ \\
\hline PEF\%p & $\begin{array}{l}\mathrm{BL}^{2}: 53.7 \% \mathrm{p} \pm 12.6 \\
\text { Change } \mathrm{BL} \text { to week } 52^{3} \text { : } \\
2.32 \% \mathrm{p} \\
(-2.48 ; 7.11)\end{array}$ & $\begin{array}{l}\mathrm{BL}^{2}: 54.0 \% \mathrm{p} \pm 14.2 \\
\text { Change } \mathrm{BL} \text { to week } 52^{3}: \\
-5.59 \% \mathrm{p} \\
(-10.54 ;-0.63)\end{array}$ & $\begin{array}{l}7.90 \% p \\
(2.23 ; 13.57) \\
p=0.007\end{array}$ \\
\hline FVC\%p & $\begin{array}{l}\mathrm{BL}^{2}: 56.2 \% \mathrm{p} \pm 17.0 \\
\text { Change } \mathrm{BL} \text { to week } 52^{3} \text { : } \\
-3.05 \% \mathrm{p} \\
(-5.99 ;-0.10)\end{array}$ & $\begin{array}{l}\mathrm{BL}^{2}: 50.5 \% \mathrm{p} \pm 19.5 \\
\text { Change } \mathrm{BL} \text { to week } 52^{3}: \\
-6.54 \% \mathrm{p} \\
(-9.55 ;-3.53)\end{array}$ & $\begin{array}{l}3.49 \% p \\
(-0.06 ; 7.05) \\
p=0.054\end{array}$ \\
\hline $\mathrm{FEV}_{1} \% \mathrm{p}$ & $\begin{array}{l}\mathrm{BL}^{2}: 55.4 \% \mathrm{p} \pm 17.9 \\
\text { Change } \mathrm{BL} \text { to week } 52^{3} \text { : } \\
-1.29 \% \mathrm{p} \\
(-5.78 ; 3.19)\end{array}$ & $\begin{array}{l}\mathrm{BL}^{2}: 50.1 \% \mathrm{p} \pm 20.2 \\
\text { Change } \mathrm{BL} \text { to week } 52^{3}: \\
-7.34 \% \mathrm{p} \\
(-11.89 ;-2.78)\end{array}$ & $\begin{array}{l}6.04 \% p \\
(0.64 ; 11.45) \\
p=0.029\end{array}$ \\
\hline
\end{tabular}

${ }^{1} A l l$ data are from hospital-based spirometry measures; 'Descriptive statistics (mean; standard deviation [SD]); ${ }^{3}$ Changes from baseline and differences between the groups were estimated using Mixed Model for Repeated Measures (MMRM) with study, treatment, visit and treatment by visit interaction as fixed factors and baseline value as a covariate $B L=$ baseline; $F E V 1 \% p=$ forced expiratory volume in 1 second per cent predicted $F V C \% p=$ forced vital capacity; $P E F \% p=$ peak expiratory flow per cent predicted; $Y=$ years.

concomitant glucocorticoid use was considered in the planning of the confirmatory phase III DELOS study.

The study objective of DELOS was to test whether idebenone could slow the decline in respiratory function in patients with DMD not taking concomitant glucocorticoids. ${ }^{69}$ The 64 patients (age 10-18 years) randomised to idebenone $(n=31)$ or placebo $(n=33)$ treatment had washed out from previous glucocorticoid use prior to enrolment and did not use glucocorticoids for the treatment of the underlying disease during the 12-month follow-up period. The study met its primary endpoint demonstrating a statistically significant and clinically relevant treatment effect on PEF\%p from baseline to month 12, which was supported by the consistency in results obtained for lung volume parameters (FVC\%p, FEV $\%$ p) at the 6- and 12-month time-points measured by hospital-based spirometry or at home using a hand-held ASMA-1 device (see Figure 3). 
Published natural history data confirm that PEF\%p, FVC\%p and FEV ${ }_{1} \% p$ all show a linear decline from age 10 onwards. ${ }^{28,29}$ The treatment effect of idebenone reported in DELOS for patients 10 years and older not using concomitant glucocorticoids on PEF\%p, FVC\%p and $\mathrm{FEV}_{1} \% \mathrm{p}$ is equivalent to slowing respiratory decline by at least 1 year, which is clinically meaningful.

The findings on respiratory function parameters in the DELOS study were supported by additional clinical observations. Specifically, the proportion of patients with reductions in FVC or PCF below clinically important thresholds, known to be predictive of imminent ventilatory failure, and the reduced number of upper and lower airway tract related disease in the idebenone group, are strongly supportive for the clinical meaningfulness of the idebenone effect. ${ }^{69}$

In order to further assess the efficacy of idebenone in delaying the loss of respiratory function, data from glucocorticoid non-using patients enrolled in DELPHI and DELOS were combined for analysis (see Table 3). The combined analysis of all patients enrolled in DELPHI or DELOS demonstrated a significant decline in PEF\%p from baseline to month 12 in the placebo group compared with a slight improvement in the idebenone group, resulting in a significant difference of $7.90 \% \mathrm{p}$ in PEF\%p between treatment groups. Similar combined analyses for FVC\%p and $\mathrm{FEV}_{1} \% \mathrm{p}$ revealed consistent treatment effects in favour of idebenone.

The consistency and robustness of the findings for the combined analyses is also demonstrated in cumulative response plots where the change from baseline to the 12 month (52 week) time-point is displayed for each patient (see Figure 4). For all three respiratory function parameters there is a clear separation of the curves for idebenone-treated patients from those in the placebo group. For PEF\%p (see Figure 4A) there were fewer patients in the idebenone group who declined compared with placebo ( $50 \%$ of patients in the idebenone group compared to $78 \%$ in the placebo group declined in PEF\%p). Likewise there were fewer patients in the idebenone group who declined in PEF\%p by $10 \%$ p or more compared with the placebo group (12\% of patients in the idebenone group compared with $40 \%$ in the placebo group). Similar patterns in favour of idebenone are also seen for FVC\%p and FEV $\%$ p (see Figure 4B, C).

\section{Idebenone in the Emerging Landscape of DMD Treatment Options}

Although best practice guidelines on their dosing regimen are still lacking, glucocorticoids have beneficial effects and can slow disease progression particularly in younger, still ambulatory patients with DMD (e.g. Bushby et al. $)^{1,2}$ However, not all patients benefit to the same extent from glucocorticoids and their benefit-risk profile in older, non-ambulatory patients still needs to be established. Therapeutic approaches to partially circumvent the effect of nonsense-mutations in the dystrophin gene or to partially correct dystrophin expression by exon skipping approaches are in advanced clinical investigation. So far, it appears that their therapeutic potential is best deployed when applied in younger, ambulatory patients with the goal to preserve muscle force and function. However, therapeutic options for older, non-ambulatory patients not able to use glucocorticoids are currently lacking, which comprises approximately $40 \%$ of the entire DMD patient population 10 years and older. ${ }^{32}$ Based on the data from the randomised placebo-controlled studies summarised above, idebenone can be considered a suitable extension of the emerging landscape of treatment options for DMD. In DELOS, the firstever phase III trial in DMD with a positive outcome, significant and clinically relevant results for primary and secondary endpoints coherently showed

\section{Figure 4: Cumulative Response Plots for the Change from Baseline to Week 52 in PEF\%p (A), FVC\%p (B) and FEV $\%$ p (C)}

A

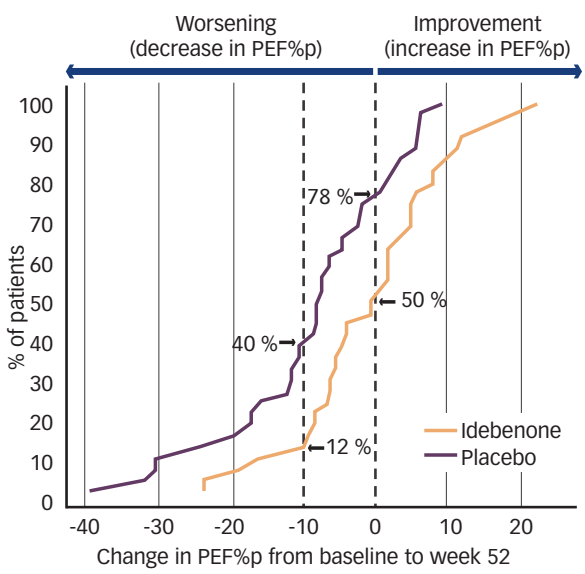

B

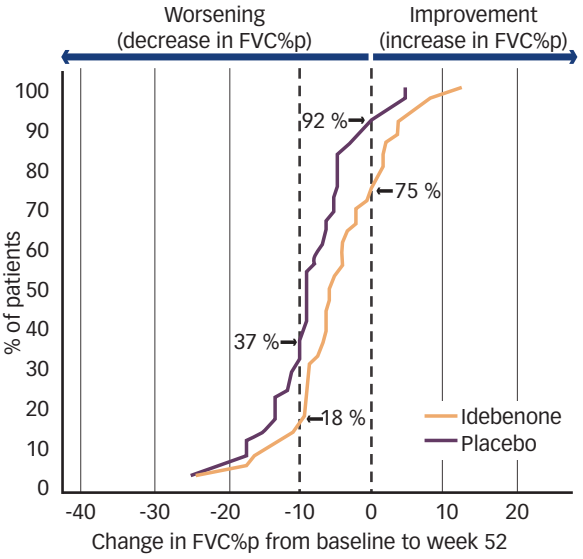

C

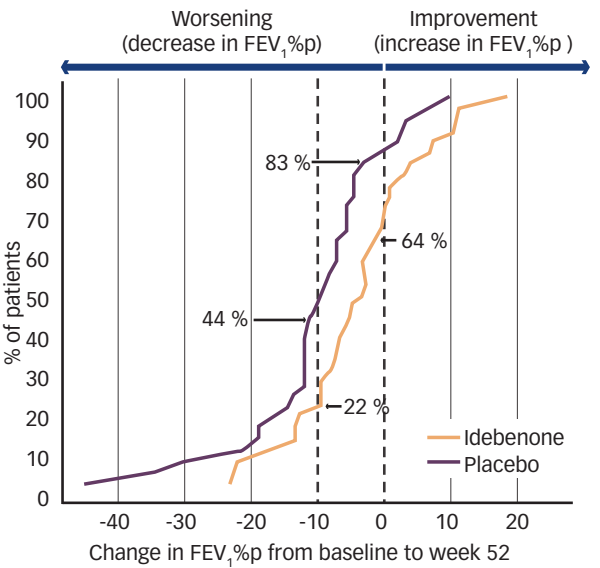

Combined analysis for patients not using concomitant glucocorticoid steroids enrolled in DELPHI or DELOS. All data are from spirometry assessments. Idebenone: $n=36$; placebo: $n=36$. FEV1\% $=$ forced expiratory volume in 1 second percent predicted; $F V C \% p=$ forced vital capacity; PEF\% $=$ peak expiratory flow percent predicted.

that idebenone reduced the loss of respiratory function. Results from the DELOS study indicate that patients who previously used glucocorticoids for the treatment of the underlying disease but did no longer tolerate their use benefit from idebenone to the same extent as patients who never took glucocorticoids. ${ }^{69}$ This is an important observation as it shows that glucocorticoids and idebenone could be used sequentially in the same patient. Although data from the current trials were obtained primarily in patients not using glucocorticoids, there is no reason a priori why idebenone could not also be exerting a treatment effect in patients using glucocorticoids concomitantly. It remains to be seen whether 


\section{Neuromuscular Disorders}

longer-term administration of idebenone will show incremental benefits over glucocorticoid treatment with regard to stabilisation of pulmonary function. Likewise, in theory, idebenone treatment might be combined with different therapeutic approaches such as exon skipping or stop-codon read-through. However, at the current time it is premature to speculate about its possible use in conjunction with any such therapy approaches.

\section{Conclusion}

Improved patient care with best-practice recommendations and the introduction of glucocorticoids has increased the quality of life and survival time of patients with DMD. Nevertheless, with increasing age loss of respiratory function continues to be a predominant cause of early morbidity and mortality. Efficacy data from randomised placebocontrolled phase II and III trials show that idebenone significantly reduced the loss of respiratory function in 8-18-year-old patients who were not taking concomitant glucocorticoids. Considering its favourable safety and tolerability profile, this oral medication could therefore become the first treatment option for patients not using glucocorticoids with the possibility to ameliorate a life-threatening complication in the ageing population of DMD patients.
1. Bushby K, Finkel R, Birnkrant DJ, et al., Diagnosis and management of Duchenne muscular dystrophy, part 1: diagnosis, and pharmacological and psychosocial management, Lancet Neurol, 2010;9:77-93.

2. Bushby K, Finkel R, Birnkrant DJ, et al., Diagnosis and management of Duchenne muscular dystrophy, part 2: implementation of multidisciplinary care, Lancet Neurol 2010;9:177-89.

3. MCDonald CM, Abresch RT, Carter GT, Profiles of neuromuscular diseases, Am J Phys Med Rehabil, 1995;74: S70-S94.

4. Hahn A, Bach JR, Delaubier A, et al., Clinical implications of maximal respiratory pressure determinations for individuals with Duchenne muscular dystrophy, Arch Phys Med Rehabil, 1997;78:1-6.

5. Suárez AA, Pessolano FA, Monteiro SG, et al., Peak flow and peak cough flow in the evaluation of expiratory
muscle weakness and bulbar impairment in patients muscle weakness and bulbar impairment in patients
with neuromuscular disease, Am J Phys Med Rehabil, with neuromusc

6. Vincken WG, Elleker MG, Cosio MG, Flow-volume loop changes reflecting respiratory muscle weakness in chro neuromuscular disorders, Am J Med, 1987;83:673-80.

7. Griggs RC, The use of pulmonary function testing as a quantitative measurement for therapeutic trials, Muscle \& Nerve, 1990;Suppl.:30-4.

8. Inkley SR, Oldenburg FC, Vignos PJ, Pulmonary function in Duchenne muscular dystrophy related to stage of disease, Am J Med, 1974;56:297-306.

9. Rideau Y, Jankowski LW, Grellet J, Respiratory function in the Rideau Y, JankowsKI LW, Grellet J, Respiratory function in th

10. Khan Y, Heckmatt IZ, Obstructive apnoeas in Duchenne muscular dystrophy, Thorax, 1994;49:157-61.

11. Tzelepis GE, Zakynthinos S, Vassilakopoulos T, et al. Inspiratory maneuver effects on peak expiratory flow: Role of lung elastic recoil and expiratory pressure, Am J Respir Crit Care Med, 1997;156:1399-404.

12. Humbertclaude V, Hamroun D, Bezzou K, et al., Motor and respiratory heterogeneity in Duchenne patients: Implication for clinical trials, Eur J Paediatr Neurol, 2012;16:149-60

13. Quanjer PH, Stocks J, Polgar G, et al., Compilation of reference values for lung function measurements in children, Eur Respir J Suppl, 1989;Suppl. 4:184S-261S.

14. Hankinson IL, Odencrantz JR, Fedan KB, Spirometric reference values from a sample of the general U.S. population, Am J Respir Crit Care Med, 1999:159:179-87.

15. Finder JD, Birnkrant D, Carl J, et al., Respiratory care of the patient with Duchenne muscular dystrophy: ATS consensus statement, Am J Respir Crit Care Med, 2004:170:456-65.

16. Birnkrant DJ, Panitch HB, Benditt JO, et al., American College of Chest Physicians consensus statement on the respiratory and related management of patients with Duchenne muscular dystrophy undergoing anesthesia or sedation, Pediatrics, 2007;132:1977-86.

17. Birnkrant DJ, Bushby KMD, Amin RS, et al., The respiratory management of patients with Duchenne muscular dystrophy: A DMD care considerations working group specialty article Pediatr Pulmonol, 2010;45:739-48.

18. Phillips MF, Quinlivan RCM, Edwards RHT, Calverley PM, Changes in spirometry over time as a prognostic marker in patients with Duchenne muscular dystrophy, Am I Respir Crit Care Med, 2001:164:2191-4.

19. Pelligrino $R$, Viegi G, Bruscasco RO, et al., Interpretative strategies for lung function tests, Eur Respir J, 2005;26:948-68

20. Becklake MR, Helms R, Lebowitz MD, et al., NHLBI workshop summary. Longitudinal analysis in pulmonary disease epidemiology, Am Rev Respir Dis, 1988;137:1241-3.

21. Kanner RE, Renzetti AD, Stanish WM, et al., Predictors of survival in subjects with chronic airflow limitation, Am J Med, 1983;74:249-55

22. Traver $\mathrm{GA}$, Cline MG, Burrows $B$, Predictors of mortality in chronic obstructive pulmonary disease. A 15-year follow-up study, Am Rev Respir Dis, 1979;119:895-902.

23. Anthonisen NR, Wright EC, Hodgkin JE, Prognosis in chronic obstructive pulmonary disease, Am Rev Respir Dis, 1986:133:14-0.

24. Hukins CA, Hillmann DR, Daytime predictors of sleep hypoventilation in Duchenne Muscular Dystrophy, Am J Respir Crit Care Med, 2000:161:166-70

25. Gauld LM, Boynton A, Relationship between peak cough flow and spirometry in Duchenne muscular dystrophy, Pediatr Pulmonol, 2005;39:457-60
26. Bach JR, Ishikawa Y, Kim H, Prevention of pulmonary morbidity for patients with Duchenne muscular dystrophy, Chest, 1997;112:1024-8.

27. Tzeng AC, Bach JR, Prevention of pulmonary morbidity for patients with neuromuscular disease, Chest, 2000;118:1390-6.

28. Abresch RT, MCDonald CM, Henricson EK, et al., Pulmonary function characteristics of boys with Duchenne Muscular Dystrophy : Data from the CINRG longitudinal study project, Neuromuscul Disord, 2013;23:802.

29. Mayer OH, Finkel RS, Rummey C, et al., Characterization of pulmonary function in Duchenne Muscular Dystrophy, Pediatr Pulmonol, 2015;50:487-94.

30. Moxley RT, Ashwal S, Pandya S, et al., Practice parameter: corticosteroid treatment of Duchenne dystrophy: report of the Quality Standards Subcommittee of the American Academy of Neurology and the Practice Committee of the Academy of Neurology and the Practice Committee
Child Neurology Society, Neurology, 2005;64:13-20.

31. Child Neurology Society, Neurology, 2005;64:13-20. Duchenne muscular dystrophy, I Pediatr, 2001;138:45-50.

32. Henricson EK, Abresch RT, Cnaan A, et al., The cooperativ international neuromuscular research group Duchenne natural history study: Glucocorticoid treatment preserves clinically meaningful functional milestones and reduces rate of disease progression as measured by manual muscle testing and other commonly used clinical trial outcome measures, Muscle \& Nerve, 2013:48:55-67.

33. Biggar $W$, Harris V, Eliasoph L, Long-term benefits of deflazacort treatment for boys with Duchenne muscular dystrophy in their second decade. Neuromuscul Disord, 2006:16:249-55.

34. King WM, Ruttencutter R, Nagaraja HN, et al., Orthopedic outcomes of long-term daily corticosteroid treatment in Duchenne muscular dystrophy, Neurology, 2007;68:1607-13.

35. Manzur A, Kuntzer T, Pike M, Swan A, Glucocorticoid corticosteroids for Duchenne muscular dystrophy, Cochrane Database Syst Rev, 2008;1:1-72.

36. Connolly AM, Schierbecker J, Renna R, Florence J, High dose weekly oral prednisone improves strength in boys with Duchenne muscular dystrophy, Neuromuscul Disord 2002;12:917-25.

37. Abresch RT, MCDonald CM, Henricson EK, et al., Pulmonary function characteristics of boys with Duchenne Muscular Dystrophy by age groups, ambulatory status and steroid use Neuromuscul Disord, 2013;23:801-2.

38. Cardoso SM, Pereira C, Oliveira R, Mitochondrial function is differentially affected upon oxidative stress, Free Radic Biol Med, 1999;26 3-13.

39. Brookes PS, Yoon Y, Robotham JL, et al., Calcium, ATP, and ROS: a mitochondrial love-hate triangle, Am J Physiol Cell Physiol, 2004;287:C817-33.

40. Peng TI, Jou MJ, Oxidative stress caused by mitochondrial calcium overload, Ann N Y Acad Sci, 2010;1201: 183-188.

41. Dunn JF, Radda GK, Total ion content of skeletal and cardiac muscle in the mdx mouse dystrophy: Ca2+ is elevated at all ages, J Neurol Sciences, 1991;103:226-31.

42. Culligan $\mathrm{K}$, Ohlendieck $\mathrm{K}$, Abnormal calcium handling in muscular dystrophy, Basic App/ Myol, 2002;12: 147-157.

43. Scholte HR, Luyt-Houwen I, Bush H, Jennekens F, Muscle mitochondria from patients with Duchenne muscular dystrophy have a normal beta oxidation, but an impaired dystrophy have a normal beta oxidation, but an impaired
oxidative phosphorylation, Neurology, 1985:35:1396-7.

44. Lucas-Heron B, Schmitt N, Ollivier B, Muscular dystrophy: possible role of mitochondrial deficiency in muscle
polat degeneration processes, J Neurol Sci, 1990;95:327-34.

45. Even PC, Decrouy A, Chinet A. Defective regulation of energy metabolism in mdx-mouse skeletal muscles, Biochem $J_{\text {, }}$ 1994;304:649-54

46. Sperl W, Skladal D, Gnaiger E, et al., High resolution respirometry of permeabilized skeletal muscle fibers in the diagnosis of neuromuscular disorders, $\mathrm{Mol}$ Cell Biochem, 1997;174:71-8

47. Kuznetsov AV, Winkler K, Wiedemann FR, Impaired mitochondrial oxidative phosphorylation in skeletal muscle of the dystrophin-deficient mdx mouse, Mol Cell Biochem, 1998;183:87-96.

48. Passaquin $\mathrm{AC}$, Renard M, Kay L, Creatine supplementation reduces skeletal muscle degeneration and enhances mitochondrial function in mdx mice, Neuromuscul Disord, 2002;12:174-82.

49. Onopiuk M, Brutkowski W, Wierzbicka K, et al., Mutation in dystrophin-encoding gene affects energy metabolism in mouse myoblasts, Biochem Biophys Res Commun 2009;386:463-6

50. Godin R, Daussin F, Matecki S, et al., Peroxisome proliferatoractivated receptor $\gamma$ coactivator1- gene $\alpha$ transfer restores mitochondrial biomass and improves mitochondrial calcium handling in post-necrotic mdx mouse skeletal muscle, J Physiol, 2012;590:5487-502

51. Schuh RA, Jackson KC, Khairallah RJ, et al., Measuring mitochondrial respiration in intact single muscle fibers, $A m J$ Physiol Regul Integr Comp Physiol, 2012;302:R712-R719.

52. Percival JM, Siegel MP, Knowels G, Marcinek DJ, Defects in mitochondrial localization and ATP synthesis in the mdx mouse model of Duchenne muscular dystrophy are not alleviated by PDE5 inhibition, Hum Mol Genet, 2013:22:153-67.

53. Cole M., Rafael J, Taylor DJ, et al., A quantitative study of bioenergetics in skeletal muscle lacking utrophin and bioenergetics in skeletal muscle lacking utrophin and

54. Rybalka E, Timpani CA, Cooke MB, et al., Defects in mitochondrial ATP synthesis in dystrophin-deficient mdx skeletal muscles may be caused by Complex I insufficiency, PLOS ONE, 2014;9:e115763.

55. Millay DP, Sargent MA, Osinska H, et al., Genetic and pharmacologic inhibition of mitochondrial-dependent necrosis attenuates muscular dystrophy, Nature Medicine 2008; 14:442-7.

56. Selsby JT, Morine KJ, Pendrak K, et al., Rescue of dystrophic skeletal muscle by PGC-1alpha involves a fast to slow fiber type shift in the mdx mouse, PLOS ONE, 2012;7:e30063.

57. Chen YW, Zhao P, Borup R, Hoffman EP, Expression profiling in the Muscular Dystrophies: Identification of novel aspects of molecular pathophysiology, J Cell Biol, 2000; 151:1321-36.

58. Timmons JA, Larsson $\mathrm{O}$, Jansson $\mathrm{E}$, et al., Human muscle gene expression responses to endurance training provide a novel perspective on Duchenne Muscular Dystrophy. FASEB J, 2005;19:750-60.

59. Gueven N, Woolley K, Smith J, Border between natural product and drug: Comparison of the related benzoquinones idebenone and coenzyme Q10, Redox Biology, 2015;4:289-95.

60. Jaber S, Polster BM, Idebenone and neuroprotection: antioxidant, pro-oxidant, or electron carrier? , J Bioenerg Biomembr, 2014;47:111-8.

61. Rauchová H, Vrbacký M, Bergamini C, et al., Inhibition of glycerophosphate-dependent $\mathrm{H} 2 \mathrm{O} 2$ generation in brown fat mitochondria by idebenone, Biochem Biophys Res Commun, 2006;339:362-6.

62. Haefeli R H, Erb M, Gemperli AC, et al., NQ01-dependent redox cycling of idebenone: Effects on cellular redox potential and energy levels, PLOS ONE, 2011;6.

63. Giorgio V, Petronilli V, Ghelli A, et al., The effects of idebenone on mitochondrial bioenergetics, Biochim Biophys Acta, 2012;1817:363-9.

64. Erb M, Hoffmann-Enger B, Deppe $H$, et al., Features of idebenone and related short-chain quinones that rescue ATP levels under conditions of impaired mitochondrial complex I, PLOS ONE 2012;7.

65. Mordente A, Martorana GE, Minotti G, Giardina B, Antioxidant Properties of 2, 3-Dimethoxy-5-methyl- 6- (10-hydroxydecyl) -1, 4-benzoquinone (Idebenone), Chem Res Toxicol, 1998;11:54-63.

66. Gil J, Almeida S, Oliveira CR, Rego AC, Cytosolic and mitochondrial ROS in staurosporine-induced retinal cell apoptosis, Free Radic Biol Med, 2003:35:1500-14.

67. Buyse GM, Van Der Mieren G, Erb M, et al., Long-term blinded placebo-controlled study of SNT-MC17/idebenone in the dystrophin deficient mdx mouse: Cardiac protection and improved exercise performance, Eur Heart $J$, 2009;30:116-24

68. Buyse GM, Goemans N, van den Hauwe M, et al., Idebenone as a novel, therapeutic approach for Duchenne muscular dystrophy: Results from a 12 month, double-blind, randomized placebo-controlled trial, Neuromuscul Disord, 2011;21:396-405.

69. Buyse GM, Voit T, Schara U, et al., Efficacy of idebenone on respiratory function in patients with Duchenne muscular dystrophy not using glucocorticoids (DELOS): a doubleblind randomised placebo-controlled phase 3 trial, Lancet, 2015;385: 1748-57.

70. Buyse GM, Goemans N, Van Den Hauwe M, Meier T, Effects of glucocorticoids and idebenone on respiratory function in patients with duchenne muscular dystrophy, Pediatric Pulmonology, 2013;48:912-20. 